\title{
TIMELY AND COMPELLING RESEARCH FOR THE FIELD OF LEARNING DISABILITIES: IMPLICATIONS FOR THE FUTURE
}

\author{
Margaret E. King-Sears, Daniel J. Boudah, Marilyn W. Goodwin, \\ Marshall H. Raskind, and H. Lee Swanson
}

\begin{abstract}
SYNTHESIS OF ARTICLES DISCUSSED AS PART OF THE RESEARCH SYMPOSIUM AT THE 25TH INTERNATIONAL CONFERENCE ON LEARNING DISABILITIES BY THE COUNCIL FOR LEARNING DISABILITIES, OCTOBER 11, 2003.

Newly nominated "must reads" can be found on the Web at: www.cldinternational.org after the CLD October 2004 International Conference (click on "scholarly initiatives").

Authors are listed alphabetically after the first author, who consolidated the 2003 Research Symposium panelists' commentaries, and the CLD Research Committee chairperson, who organized the 2003 Research Symposium.
\end{abstract}

MARGARET E. KING-SEARS, Ph.D., is professor, Johns Hopkins University. DANIEL J. BOUDAH, Ph.D., is assistant professor, University of North Carolina. MARILYN W. GOODWIN, Ph.D., is associate professor, Texas State University. MARSHALL H. RASKIND, Ph.D., Frostig Center; Schwab Learning. H. LEE SWANSON, Ph.D., is professor, University of California-Riverside.

Educators attempting to keep up with the most recent research readily acknowledge that there is too much to read and too little time for reading. Each fall, the Research Committee of the Council for Learning Disabilities (CLD) sponsors a Research Symposium Panel in which panelists, after reviewing recent literature pertinent to the field of learning disabilities (LD), prioritize selections of "must reads" for educators (see Table 1). Symposium panelists apply individualized criteria in selecting their readings, and intentionally no attempt is made to influence perspectives or parameters to ensure autonomy for each panelist's recommendations.

The topics reflect today's issues as well as the need for continued emphasis on substantive and scientific work that examines learning theories and educational practices for students with LD. Moreover, exploration of the practicalities and complexities of identifying and utilizing research-based practices with students with LD is evident in this year's recommendations. Selected readings and commentary from the panelists converge around three topics currently receiving widespread attention in the field of LD:

1. Increasing the widespread implementation of research-based practices in schools, more commonly called "bringing to scale" or "scaling up" practices.

2. Continuing to explore practices that are specialized, individualized, and responsive to the unique 
needs of students with different types of learning disabilities, as well as focusing beyond schoolbased learning to lifelong success.

3. Examining the implications of applying new identification and eligibility criteria for students with LD in applying a response to intervention (RTI) model.

The first topic that emerges in the readings selected by the panelists surrounds the difficulties of scaling up the use of research-based practices to ensure more widespread use in schools and classrooms. Although translating research into classroom practice is not a new notion, we are learning more about how to respond to barriers and difficulties educators face in using and adhering to key factors while implementing well-researched practices.

The second topic across panelists' recommendations is the importance of continuing to focus on truly specialized instruction for students with LD. Even as the field struggles to increase the use of what we already know works in classrooms, it is crucial to continue research on techniques that have the capacity for being more responsive to the needs of students with LD. Moreover, responsiveness entails considerations for promoting academic achievement and developing resiliency toward lifelong success.

The third topic woven among panelists' recommended readings is the question of how to implement an RTI model. RTI methods emphasize the use of effective instructional tools and behaviors used for all students who are not progressing as expected in the primary grades, particularly in reading. Intended benefits of RTI methods include:

- Students who are at risk for school failure are availed of an RTI "bridge" intended to close the gap between their performance and that of their sameage peers.

- All students receive effective instructional procedures in which their progress is monitored and responsive instruction occurs.

- Fewer students end up in programs for students with LD because their learning issues are addressed quickly and effectively.

- More students who are found eligible for special education services are more likely to have "true" learning disabilities.

With these three topics as an advance organizer, the following summaries identify the "must read" selections from each panelist's perspective. Their commentary contextualizes the information for its importance at this time, provides a rationale for how the information can be used, and identifies some views of the future for the field of LD.

\section{IDENTIFICATION, INSTRUCTION, TEACHER PREPARATION, AND "SCALE"}

\section{J. Boudah}

My list of "must reads" from the recent year's literature reflects four connected topics or themes: (a) current issues of identification, (b) effective instruction and programming, (c) teacher education (specifically the use of web-based instruction), and (d) change as reflected in the concept of "scale."

Vaughn, Linan-Thompson, and Hickman (2003) conducted a significant research study in which they tested the validity of the response-to-intervention (RTI) concept for identifying reading disabilities/LD. They operationalized RTI factors by providing students who were not proficient readers with successive weeks (i.e., 10week segments) of intensive instruction while continuing to assess the students and "release" those who "caught up" to a predetermined criterion for reading proficiency.

Participants in their study were 45 second graders who were not performing at grade level on state measures of reading. Students received 10 weeks of intensive instruction in phonemic awareness, sound-letter relationships and word families, fluency, comprehension, and spelling. Performance was assessed through several measures, and students who met exit criteria for performance were removed from the intervention group and placed into general education programs. That is, when students' data - or their response to instruction were sufficient, the students returned to the general education setting for continued reading instruction. Students whose performance indicated a continued need for intensive instruction, on the other hand, received another 10 weeks of intensive instruction. Students were again assessed, and some exited. Those who did not exit participated in a third round of 10 weeks of intensive instruction. At the conclusion, some students exited, and those who remained received additional, more intensive instruction.

In addition to the 10-week assessments, all students were pre- and posttested. Posttest comparisons showed that the group of students who received 40 weeks of intensive instruction were significantly different on three measures - fluency, rapid naming, and comprehension. The authors concluded that it is these students who should be eligible for special education services as LD, that is, those who did not respond sufficiently well to treatment (in reading, at least).

Vaughn et al.'s study was well conceived, used sound measures, and included excellent analyses. Indeed, it may be a blueprint for how RTI should be carried out. Remaining questions or issues surrounding RTI include: 
- How do we decide the criterion or cutoff for acceptable performance?

- What kinds of interventions should be included in RTI?

- For what duration and to what level of intensity should RTI occur?

- What kinds of training are necessary for teachers who deliver RTI treatments?

- How is RTI operationalized for secondary learners (presuming differences in operationalization at the secondary v. elementary level)?

Furthermore, on a conceptual level it is difficult to know how to separate students with LD from other students who do not respond to treatment. In other words, if RTI addresses some level of low performance, is that really a disability? If the answer is yes, we need to first return to the criterion question (i.e., what is the criterion or cutoff score for eligibility into an RTI and for exit from an RTI?). Second, we have to rethink our traditional paradigm of LD as being somehow a neurological, individual pathology. Finally, we must consider other forms of $\mathrm{LD}$, including written language or math.

There are other questions and issues to be addressed as well. These and others are addressed marvelously in the Learning Disabilities Research \& Practice special issue co-edited by Vaughn and Fuchs (2003), which features articles by some of the most thoughtful writers in the field today.

Vaughn and Fuchs set the table by laying out some of the same questions mentioned above, in addition to others such as what proportion of children are likely to be false positives in a RTI model? When does due process come into play for parents? In the special issue of Learning Disabilities Research \& Practice, Speece, Case and Molloy (2003) address issues related to dual discrepancy, and Fuchs and his colleagues (2003) expand on a topic that he has championed in recent years: fidelity to treatment. One key point was that since RTI models rely so heavily on intervention, and if we are going to go to scale on such models of identification and service delivery, we must have highly trained teachers who can apply best practices with precision.

The remainder of my "must reads" include other topics that we need to consider because issues and practices related to identification do not, and cannot, operate independently of issues related to effective instruction and service delivery, teacher training, and changes in the field that must be, by inference to "scale." Hence, my next recommendation is particularly important for policymakers at state and local levels.

Denton, Foorman, and Mathes (2003) encapsulate the characteristics of several highly successful programs, particularly in Title 1 schools, for addressing low-performing readers, those with $\mathrm{LD}$, and perhaps those at risk for gaining that label later in life. Some of their findings and conclusions are not surprising, perhaps, but serve to remind us of many of the contextual variables that must be in place for RTI to produce desirable results, including ongoing teacher training, administrative leadership, program flexibility, smallgroup and individual attention, and ongoing databased assessment.

We depend on truly highly qualified teachers to carry out RTI interventions. But where are these people, and how do they become "highly qualified"? Districts in every state are struggling just to staff some of the classrooms where students with LD and students with other disabilities are served. In North Carolina, for example, every district reported hiring teachers on emergency credentials or through lateral entry. This unfortunate situation exists across the United States, whether in a wealthy or a poor district, a suburban, rural, or urban district.

Teachers hired on emergency or provisional status do not begin school in August or September as "highly qualified" in terms of what is necessary to implement RTI, or perhaps not even to meet No Child Left Behind's emerging standards for "highly qualified" teachers (NCLB, 2001; USDoED, 2003; USDoED, 2004). Teachers hired on emergency or provisional status may have undergraduate or graduate degrees in a core academic subject, or they may have credentials in fields where pedagogy has not been the primary focus (e.g., business, military).

If RTI were to become a reality some time in the future, we will be entrusting educators who may not have sufficient training to carry it out to benefit children with LD. These educators need support. Indeed, they need an intensive level of support that parallels the intensity that students with LD need. Those who conduct teacher training and professional development must provide training and support through both traditional and alternative models of teacher preparation in order to match the demands of teachers who are exhausting themselves during daytime hours at schools.

And we need to do so before teachers are so exhausted that they burn out and leave the profession. It appears from other recent literature that the challenge of retaining the growing numbers of teachers who enter the job through lateral entry or similar means is even greater than for teachers who are trained through traditional university-based programs. To that end, Sun, Bender, and Fore (2003) describe a web-based licensure (not degree) program in Georgia.

This is a very thoughtful piece indeed, with suggestions (e.g., focus initially on highly sought courses in critical shortage areas $\mathrm{v}$. core courses; build in a solid evaluation component) that I can relate to as one who 


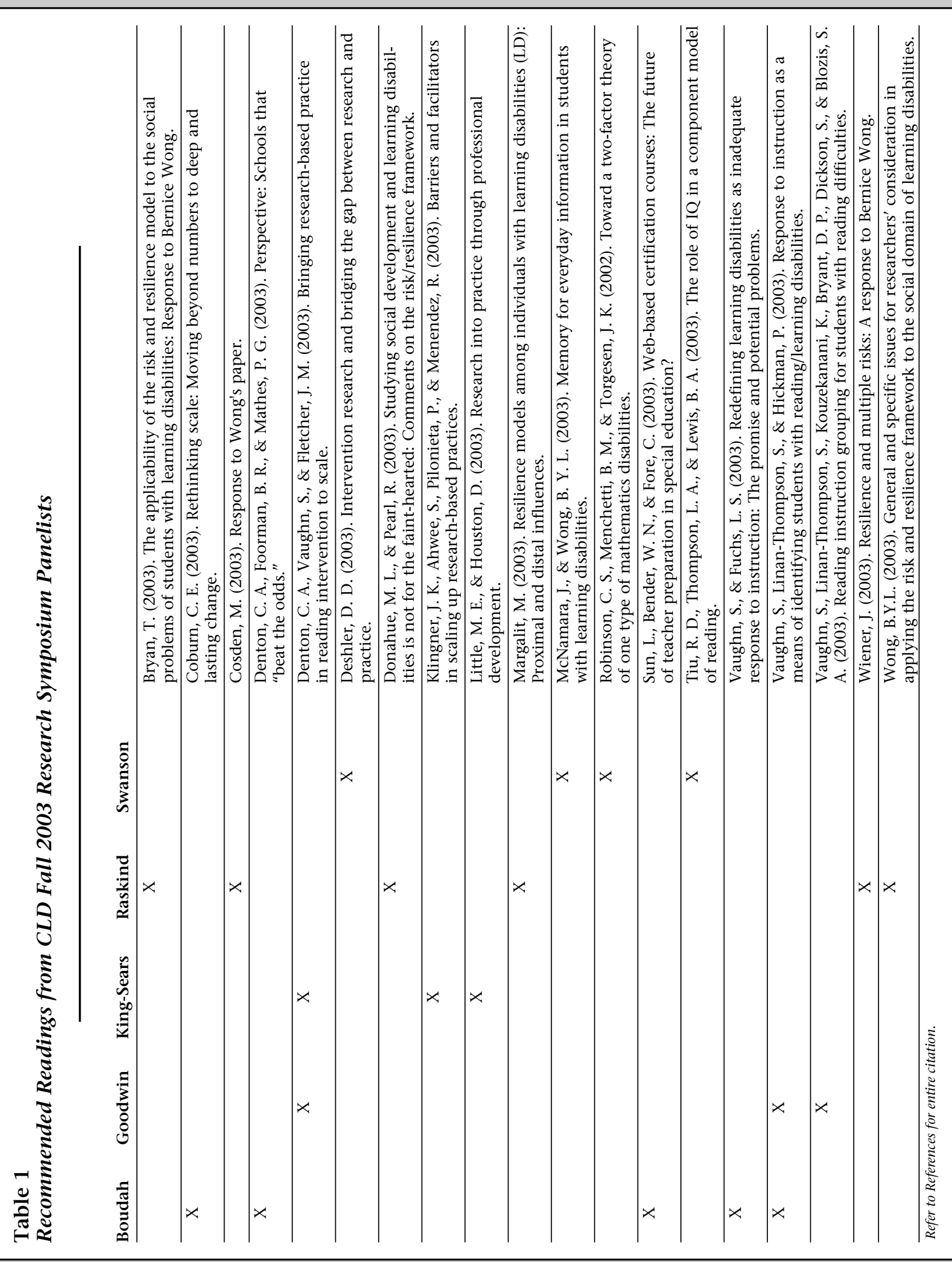


has been thrust into changing a traditional program to a licensure program that does not operate on campus during "regular business" hours. Teacher educators and professional development providers who have not yet been involved in online courses and professional development venues will likely find themselves exposed soon. Sun et al. (2003) provide insights and information that prompt critical examination of the responsiveness and quality of web-based programs.

My last "must read" addresses issues of bringing practices to "scale." Coburn (2003), while not a special educator, makes a number of valid observations about the process of change and the way we talk about taking practices to scale. Think back to RTI: If RTI becomes a reality, we will have a lot of work to do to bring the practices, as well as some significant changes in culture, to scale. We talk about "scale" most often in terms of quantity - of schools, districts, teachers, and even particular practices implemented. Scale, clearly, has as much to do with depth and breadth of implementation of practices, sustainability, and ownership. These are the key issues that Coburn brings to our attention in this piece. He provides insightful and provocative information for us to consider as researchers, teacher educators, and collaborators in the process of school reform and change.

\section{RESEARCH GAP, MEMORY FOR FUNCTIONAL INFORMATION, IQ, READING, AND MATH DISABILITIES}

\section{H. L. Swanson}

In the first article I chose to include here, Deshler (2003) describes some of the major factors that account for the gaps that exist between special education research and classroom practice. He also presents four major policy recommendations to be considered by funding sources. In recapping some of the major reasons for the difficulty in practitioners embracing research-validated practices, Deshler suggests that one reason is the perception that researchers fail to involve practitioners in the research process. This separation results in erroneous perceptions that (a) issues of validation of practices are unresolved; (b) educational research lacks relevance to practitioners; (c) researchers fail to produce usable interventions; and (d) researchers generally fail to produce interventions that have specificity to practitioners.

What I found particularly interesting in this article was that Deshler (2003) went beyond the traditional suggestions, such as contextualizing factors including teachers, to ensure internal and external validity. Clearly, he heeds the call among all of us to promote use of scientifically based practices in special educa- tion. He also discusses some mechanisms on which special education research dollars can be spent, including the need for replicating and validating practices on a large scale. Finally, he cautions that we have no miracle cures and that certain "catch phrases" (referring to "scientifically based research") require judicious interpretation (i.e., although some research is scientifically sound, it may not translate to important, practical, and meaningful classroom practices).

To bridge the gap between research and practice, we need to:

1. Establish practices that ensure public review and input.

2. Develop mechanisms that promote the development of more powerful and reliable discoveries, such as identifying and prioritizing specific research areas.

3. Provide some freedom to educational agency leaders in terms of how educational investments are made.

4. Increase the quantity of and criteria for research scholars who make judgments on which research areas receive funding.

Finally, Deshler (2003) emphasizes that an atmosphere of research must be evident across all levels of education. That is, a clear and focused emphasis on research must exist from the funding source for conducting research to the practitioner who implements research-based practices.

My second recommended reading is research conducted by McNamara and Wong (2003), who examined memory issues for students with $\mathrm{LD}$, specifically students' retention of everyday functional information. This is important research because the authors attempted to examine some of the common constructs of LD, such as memory deficits, with everyday sorts of tasks.

McNamara and Wong (2003) looked at laboratory measures, and then correlated them with everyday experiences such as remembering workshop-related procedures in terms of information related to library, remembering information on money, and remembering common commercial signs (e.g., fast-food signs). Although it may come as no surprise that students with LD do poorly on a laboratory test, it may be surprising to learn they also do poorly on everyday kinds of recall tasks. McNamara and Wong's research is particularly important because few studies have documented some of the constructs (e.g., memory) that underlie LD within the context of everyday situations and tasks.

My third "must read" is by Tiu, Thompson, and Lewis (2003), who examined how IQ plays out related to reading. The authors investigated how processes that involve reading differ between children with reading disabilities and those without reading disabilities. As 
many may be aware, the literature seems to suggest that IQ is irrelevant when making predictions of reading, except that IQ does predict performance on reading comprehension measures. However, the notion seems to be that you cannot separate the performance of children who are considered poor readers but have above average IQ (discrepancy-defined samples) from children who have below-average IQ and poor reading (referred to in the literature as "garden variety" poor readers).

Nevertheless, Tiu et al. (2003) suggest that there might be a role for IQ in predicting reading. Their sample is part of an ongoing study in the Cleveland area. Students were approximately 10 years old, and included children with reading disabilities and children without reading disabilities. Their statistical analyses using regression results suggest that processing speed and memory, for example, play a role in predicting reading, but that IQ also does. The authors argue that although reading disabilities must be identified through word identification tasks, IQ remains an important construct.

My final recommended reading is by Robinson, Menchetti, and Torgesen (2002), who present a model that seems to suggest that math disabilities are related to two factors: a weakness in the phonological system or number sense. In the case of the phonological system, they argue that auditory and phonological features associated with numbers and number facts are not tied to the phonological system, making it impossible for the student to "pull up" a distinct representation of numbers and number facts. Thus, it is difficult for students with math disabilities to retrieve mathematical facts due to hindrances in the phonological system. Phonological processing is considered an intrinsic process, with other skills - such as phonological awareness - built upon it. In other words, phonological awareness is not a basic intrinsic process, but an acquired skill. Number sense is an acquired skill. The authors argue against the possibility that semantic representations might underlie difficulties in having a certain number sense. This is a very provocative article about an area that we know relatively little about.

\section{THE GOOD NEWS IN READING INTERVENTIONS FOR STUDENTS WITH LD}

\section{W. Goodwin}

My first recommended reading focuses on the effects of three group sizes on students' achievement (Vaughn, Linan-Thompson, Kouzekanani, Bryant, Dickson, \& Blozis, 2003). Participants were second graders who were struggling readers. The group sizes were 1:1 (1 teacher with 1 student), 1:3 (1 teacher with 3 students), and 1:10 (1 teacher with 10 students). All students received the same supplemental reading intervention for the same number of sessions, thus holding intervention type and intensity constant and enabling a focus on the varying group size. The performance of students who were either MES (monolingual English speakers) or ELL (English language learners) was also examined.

Findings indicated that, overall, students made significant gains following the intervention and that the gains were maintained over time. In addition, gains in comprehension, phoneme segmentation, and fluency yielded high effect sizes. Specifically, instruction that was 1:1 was superior to 1:10 instruction for comprehension and phoneme segmentation for both the MES and ELL students. Monolingual speakers performed better on fluency in groups of 1:1 than 1:10; for ELL students, fluency performance was significantly greater in the 1:3 group than in the 1:10 group. For reading comprehension, both the 1:1 and 1:3 groups were superior to the 1:10 group. The 1:1 group was not superior to the 1:3 group on any outcome measure. Thus, it appears that both $1: 1$ and 1:3 are highly effective intervention group sizes for supplemental reading instruction.

Given the current focus at both national and state levels on preventing reading failure, school district administrators are making decisions about how to best provide supplemental reading interventions for students who struggle with reading or are at risk for reading disabilities. Perhaps the most practical implications from this study are that struggling readers benefit from an intensive, explicit approach to reading instruction. Although Vaughn et al. (2003) were unable to determine which components of the intervention program may have been associated with specific gains for ELL students, these students performed as well as, or better than, monolingual students. Considering the dismal progress made by many ELL students who struggle with reading in both general and special education classrooms (Gersten \& Jimenez, 1998; Goldenberg \& Gallimore, 1991; Vaughn, Moody, \& Schumm, 1998), the progress made by the students participating in this explicit supplemental instruction is noteworthy. Thus, the results lend support to the idea that, broadly speaking, the cognitive processes required for reading for ELL students are much the same as for all learners.

Vaughn et al.'s (2003) findings that students who received 1:1 instruction did not make higher gains than students taught in group sizes of 1:3 is valuable given the limited resources of most school districts. It benefits students in one of two ways. It allows more students to be given supplementary instruction, or it allows the same number of students additional time and practice.

My second recommended reading involves a response-to-intervention (RTI) model that was system- 
atically implemented to determine which students benefited from supplemental reading instruction. The authors, Vaughn, Linan-Thompson, and Hickman (2003), also examined the RTI model as a means of identifying students with reading/learning disabilities. Reading was the target area because most students with LD have reading problems. Second grade was selected because early identification of students with LD (below third grade) is critical, and because there is a larger research base on reading interventions at that level.

Forty-five second-grade students identified as at risk for reading problems from three schools participated. The authors examined the impact of supplemental reading instruction and identified criteria marking students' readiness to exit from the supplemental reading instruction. Vaughn et al. (2003) posited that students whose progress was not impacted sufficiently (i.e., their response to instruction) using the supplemental reading instruction might have serious reading problems and might be considered eligible for special education services as students with reading or learning disabilities.

The students received daily supplemental reading instruction and were assessed after 10 weeks to determine if they met criteria for exit from the supplemental reading instruction program. Students who met criteria no longer received supplemental instruction. Those who did not were regrouped, and supplemental instruction was continued for another 10 weeks. After 20 weeks of supplemental instruction, students who still had not met criteria were provided another 10 weeks of supplemental instruction. Students who never met criteria were classified as "no exit." Pretest scores on fluency, passage comprehension, and rapid naming were the significant predictors of students who did not meet exit criteria.

Noteworthy was the outcome that almost equal numbers of students met exit criteria after each interval (10 weeks, 20 weeks, 30 weeks). Furthermore, an almost equal number of students never met exit criteria ( $n=$ 11). Vaughn et al. (2003) were also interested in findings related to gender:

- Slightly more females than males were identified as at risk (20 females and 25 females).

- Relatively equivalent numbers of males and females met exit criteria at 10 and 30 weeks, but slightly more girls met exit criteria after 20 weeks ( 5 males, 9 females).

- More females than males did not meet exit criteria at all (4 males, 7 females).

These findings contribute to the ongoing research suggesting that males are not considerably more at risk for serious reading problems than females (Shaywitz, Shaywitz, Fletcher, \& Escobar, 1990). The data also provide compelling evidence that some males who are referred for assessment to determine eligibility for special education services may benefit sufficiently from supplemental instruction to eliminate the need for special education assessment due to responsiveness to more intensive supplemental instruction.

Vaughn and colleagues (2003) demonstrated that RTI should be pursued as a viable option for identifying students with reading/learning disabilities. There are two lessons from this study with respect to identification and treatment. First, by establishing a priori criteria for success and a maximum length of time for supplemental instruction (30 weeks), it was possible to identify a distinct cohort of students who require substantial support and more intensive and explicit instruction. These students can be considered as requiring special education. Second, students who were in the group that did not meet criteria after 30 weeks of supplemental instruction differed from students in the groups who met criteria on rapid naming, fluency, and word attack. Thus, these students (those who did not meet criteria after 30 weeks of supplemental instruction) demonstrated the need for extensive supplemental instruction in order to benefit from general education.

Several issues surround eligibility for special education services, particularly distinguishing students who have learning problems from students who have learning disabilities. The advantages of using RTI models address some of these issues because RTI implementation (a) provides supplemental instruction to a large number of at-risk students, (b) requires ongoing monitoring of student progress, and (c) reduces some biases inherent in traditional referral systems that depend considerably on the perceptions and interpretations of classroom teachers (MacMillan \& Speece, 1999; Speece \& Case, 2001; Ysseldyke, Algozzine, \& Epps, 1983). Based on the early findings of this study, Vaughn et al. expect that some students will benefit both initially and in the long term from supplemental instruction, but that benefits for some students will fade unless subsequent supplemental instruction is provided. Consequently, it is important that students with and without disabilities are instructed using research-based practices that are responsive to their learning needs. For that to occur, teachers need to be knowledgeable about and skilled with implementation of these practices.

My final recommended reading is about how to "scale up," or expand, the dissemination and implementation of research-based practices in classrooms. Multiple reports have provided converging evidence regarding effective instruction for students who have difficulty learning to read. Evidence-based instruction in general education classrooms must be in place in order to implement RTI models. Despite the well- 
developed knowledge base supporting the value of interventions that have been demonstrated to have positive outcomes, these interventions are not widely employed in typical classroom instruction, and models of service delivery for students with reading and learning disabilities implemented in schools are often ineffective.

Denton, Vaughn, and Fletcher (2003) note that while this need not be the case, there are many obstacles. Large-scale implementation of effective educational practices for struggling readers depends on a research agenda that directly addresses questions related to "scaling" and sustaining educational innovation. Denton et al. stress that reform depends on collaboration among researchers, educational practitioners, teacher educators, and policymakers, with the common goal of improving outcomes for students who might otherwise experience reading failure.

Over the last three decades, research on reading has increased our knowledge and understanding at an unprecedented rate. As we explore the practical implications of the widespread inclusion of students' response to intervention in decisions related to providing special education services, we must be able to reliably assume that they have been provided high-quality reading instruction. It is necessary to ensure that general classroom reading instruction is of universally high quality and that practitioners are prepared to effectively implement validated reading interventions. This is no small challenge. Denton et al. (2003) address this challenge through an analysis of factors related to bringing research-validated practices to scale, essential for the implementation of RTI models.

Denton et al.'s (2003) summary of reading research and consensus reports reveals that the following areas must be in place to enhance the reading development of all students: (a) an effective and knowledgeable teacher, (b) integration of key instructional components, (c) differentiated instruction for students with reading disabilities, (d) explicitness of instruction, and (e) bridging the gap between research and practice. In addition, successful programs for students with LD are highly related to two factors (Vaughn et al., 1998; Vaughn et al., 2000): (a) the extent to which the general education teacher has the time, skills, knowledge, and interest in providing an appropriate education for students with LD; and (b) the extent to which other personnel, such as special education teachers, are able to control their schedules and case loads so that they are able to provide explicit and systematic instruction each day to a small group of students with LD - even if for only 45 minutes.

Further insights from Denton et al. (2003) pertaining to scaling up educational innovations can come from examining such programs as Reading Recovery and
Success for All. Schools or districts must agree to follow procedures designed to ensure high-fidelity implementation when adopting either of these programs. Successfully disseminated and sustained programs such as the two mentioned above must be perceived by teachers as practical and useful. Successful programs recognize the professionalism of teachers by communicating the connection between research and real everyday classroom situations. The single most important element related to sustained implementation is the recognition by teachers that their efforts have resulted in increased student learning; that is, that the extra time and energy they have invested in implementing new practices have paid off.

True progress for students with disabilities will require that all federal agencies involved in education work together. It is to be hoped that the recent policy initiatives in reading will result in some combination of efforts. If successful, these efforts at improving reading could provide a model for other areas of educational research.

\section{RISK-AND-RESILIENCE FRAMEWORK FOR THE FIELD OF LEARNING DISABILITIES}

\section{H. Raskind}

My recommended readings are from a thematic issue of Learning Disabilities Research \& Practice (Spring 2003), in which several authors explored the value of a riskand-resilience framework for research and practice in learning disabilities (LD). Although the series of articles focuses on the social and emotional functioning of children with LD, there are implications as well for the study and practice of LD across time, domains, and contexts. Wong (2003) begins the special issue with a discussion of several general and specific issues pertaining to the risk-and-resilience framework. The subsequent articles by Wiener, Margalit, Cosden, Donahue and Pearl, and Bryan, respectively, provide responses to and commentaries on Wong's thesis.

Rather than discussing each article separately, the following synopsis highlights a number of general themes that emerge from the series. My synopsis will focus on what I thought were the most important or interesting ideas in the series, not necessarily what the authors themselves believe to be the most crucial. Similarly, my interpretation of the ideas put forth by the authors represents my perception. With the above in mind, I apologize in advance to the authors, both individually and collectively, for any misrepresentation or misinterpretation of this outstanding special series.

I begin with a general comment on the importance of a risk-and-resilience framework for LD as presented by the authors. The framework moves from the more 
traditional static deficit-oriented model of LD that focuses on specific difficulties at particular points in time and within particular contexts (e.g., academic deficits in the school-aged years), to a dynamic model that also recognizes an individual's strengths and abilities across contexts (e.g., educational, family, social, community, employment) and over time. This is not to suggest that an understanding of deficits is not important, but to emphasize that there is life beyond the school-aged years and outside of the educational context. Thus, the longitudinal/lifespan perspective offered by a risk-and-resilience perspective provides an opportunity to consider the multiple variables (i.e., risk and protective factors) that lead to positive or negative life outcomes.

There is a "spirit" of optimism in such an orientation based on knowing that, despite an early "poor prognosis" or having to face great adversity, some individuals with LD "beat the odds" and go on to lead productive, satisfying, and rewarding lives. This notion has been supported by several LD studies employing a risk-and-resilience perspective and longitudinal designs (Gerber, Ginsberg, \& Reiff, 1992; Raskind, Goldberg, Higgins, \& Herman, 1999; Werner, 1993). These studies have indicated that, while a child may have an LD, certain factors like self-awareness, internal locus of control, proactivity, realistic goal setting, and strong support systems promote positive life outcomes.

The authors of this special series brought up a number of critical issues related to employing a risk-andresilience framework in research. First, it is critical to determine whether to study (a) children at risk for developing LD in the general population, (b) LD as a risk factor (in and of itself) within the general population, or (c) the multiple risk and protective factors (and the interplay of these factors) within a population already identified as LD. Although the authors made cases for each of these perspectives, it appears that the third approach - studying the multiple factors in a specific group of children already identified as LD - would be more economical and enable a more focused and indepth understanding of the nature of LD and how it is experienced during the life course, as well as the interplay of the variables leading to specific life outcomes.

Several authors also stressed the importance of clarifying what is meant by "negative outcomes," essentially asking the question, "At risk for what?" These outcomes could include poor social relations, poor family relations, and vocational difficulties. Again, the emphasis here appears to be on moving from a limited view of academic/educational outcomes to a model that encompasses multiple domains and contexts.

Finally, an interesting idea regarding LD as a protective factor emerged. Although we typically conceive of
LD as a risk factor (possibly leading to negative outcomes), we seldom acknowledge that an LD may serve as a protective factor against negative outcomes. That is, it is possible that the support systems and accommodations that result from LD identification serve to "protect" these children, even more so than other children who are experiencing difficulties, but have not received the understanding and support necessary to cope with their problems. This is a most intriguing idea and is worthy of further exploration.

The authors of this special issue also brought up a number of intriguing points regarding interventions for children with LD within a risk-and-resilience framework. Interventions within such a framework must use strategies that are fluid and flexible rather than rigid and "lock-step," given that risk-and-resilience factors are not fixed and may change, interact differently, or have a varied impact across contexts and time. Consequently, to be effective, intervention strategies must inevitably place a greater or lesser emphasis on fostering specific protective factors or reducing certain risk factors (as may be possible) at different times in a person's life. Along these lines, consideration must be given to whether - given the specific time and circumstance - it is better to decrease certain risk factors or increase specific protective factors. Additionally, at times it may be necessary to focus on attacking seemingly "lesser" but more changeable factors.

In light of the dynamic nature of risk and protective factors, the authors noted that interventions will probably not lend themselves to the development of simplistic "packaged programs." A risk-and-resilience framework is not limited to an understanding of the factors that place an individual at risk for certain negative outcomes. Rather, it also considers those variables (and interactions between and among those variables) that buffer, mediate, or protect an individual from them. In fact, the framework also considers those factors that promote positive outcomes. This notion translates into interventions aimed not only at "fixing what's wrong," but also nurturing and developing "what's right." Therefore, risk-and-resilience interventions must focus on fostering children's strengths, talents, and special abilities. The authors also maintain that the development of interventions within a riskand-resilience framework will require a multidisciplinary team consisting of researchers, teachers, counselors, therapists, and parents. Such an intervention would do well to foster the development of protective factors throughout the school curriculum, as well as extend to familial and social contexts outside the school setting.

Ensuring the efficacy of risk-and-resilience interventions for children with LD will require research that can 
determine the effects of specific interventions not only on short-term measures, but, ultimately, on life outcomes in multiple domains. Such longitudinal research is challenging in terms of cost, time, and commitment. However, it is only through such research that we will be able to fully understand the nature of LD and the actions we have to take to ensure that children with LD grow up to lead satisfying, productive, and rewarding lives. More than a challenge, such research is our obligation.

\section{TRAVELING THE ROAD OF RESEARCH TO PRACTICE: SCALING UP FOR THE LONG JOURNEY}

\section{E. King-Sears}

My recommended readings illuminate and illustrate some of the decisions and dilemmas that arise when researchers and practitioners work together to cross the bridges leading to more research-validated techniques in school-based practices for students with learning disabilities (LD). The researchers' roads have to cross over to the practitioners' roads (i.e., the bridges!) so that the students travel the greatest distances possible. Intersections with policymakers, teacher preparation programs, staff development programs, and schoolbased implementation must occur, so that "crashes" are avoided and smooth(er) travels can occur.

Students with LD are capable of arriving at destinations of higher achievement; the authors of the following articles point out some obstacles along the way as well as routes that, when traveled, promote smoother journeys.

Denton, Vaughn, and Fletcher (2003) summarize how research-based practices in reading impact students with and without learning disabilities. Given the recent focus on distinguishing students who have reading disabilities from those who have learning disabilities as well as how critical it is that all learners receive effective reading instruction, especially in the primary grades, their summary goes beyond simply identifying effective reading instruction. Thus, Denton et al. focus on the challenges educators must overcome to ensure that all students receive effective reading instruction. They provide keen insights into the need to provoke and promote more widespread implementation of what is known about effective reading instruction. Their suggestions for multiple stakeholders illustrate the complexity of research-to-practice issues and extend another layer of this issue: "bringing to scale" or widespread implementation - of effective reading instruction for all learners. This issue is critical for students with LD in terms of early and accurate identification as well as effective and intensive early intervention. My primary focus in selecting this article is that the authors go beyond identifying effective practices for reading; they highlight the trials and triumphs of how to bring to scale research-based practices.

Klingner, Ahwee, Pilonieta, and Menendez (2003) examined the factors that contribute to teachers being characterized as high, moderate, or low implementers of research-based reading programs in inclusive settings. Students with LD constituted the highest number of students with disabilities in the inclusive settings. Klingner et al. distinguished the teachers' "labels" as high, moderate, or low implementers based on the number of times they used the particular reading methods. Further, based on these labels, they noted factors the teachers reported as hindering or helping them with implementation.

Helpful factors included administrative support, training, materials, and technical assistance and support - factors that have been widely cited for years as necessary for successfully implementing new methods. Additional helpful factors included high-implementation teachers' (a) focusing on how the new reading methods impacted students' achievement, (b) persisting in "staying with" the new method, (c) problemsolving when issues came up, (d) determining how the new methods overlapped with school or school system initiatives, and (e) making sure they implemented techniques correctly (i.e., treatment fidelity). The authors recommend focusing on moving the "moderate implementers" into the "high implementers" category, suggesting these are the teachers who might "go either way." Implications from this study illustrate the complexities of research to practice on a larger scale, and the need to involve multiple levels of stakeholders.

Little and Houston (2003) describe how Florida is using a multilevel approach to providing professional development opportunities that benefit students with and without LD. A systematic and comprehensive project design was used to select scientifically based methods for professional development, teams of educators committed to long-term involvement, and demonstration site criteria for implementation and evaluation methods. Crucial components for site selection included observation of teachers (e.g., checklist of critical teaching behaviors) as well as data-based decision-making by teachers (e.g., action research, norm-referenced assessments, curriculum-based assessment). The authors include many forms and checklists used in this ongoing statewide project that involves multiple stakeholders (i.e., personnel from universities, state department of education personnel, and school systems).

Little and Houston (2003) operationalize a different route from that described by Denton et al. (2003) and Klingner et al. (2003) for scaling up implementation of 
research-based practices in that they begin with a statewide approach that seeks implementers from across the state. Yet, all of these authors converge in their focus on a complex charge for educators at all levels - how to get more of what we know works into teachers' hands so that more learning occurs in students' heads. The implications for students with LD are enormous: if more teachers were using the best techniques we know of, students with $\mathrm{LD}$ would be more likely to be accurately identified and fewer students would be likely to have problems learning.

\section{SUMMARY}

Perspectives and summaries of the "must read" articles for the field of LD from the 2003 CLD Research Symposium panelists provide a view of the past and projections for the future. Although the panelists did not intentionally select the same articles, it is interesting to note that two articles were "must read" selections from more that one panelist: Denton, Vaughn, and Fletcher's research on scaling up the use of research-based reading practices and Vaughn, LinanThompson, and Hickman's research on RTI as a method for identifying students with reading/learning disabilities. These topics permeate the LD field in many ways. For more individuals with $\mathrm{LD}$ to receive effective and responsive instruction, their teachers must have access to research-based techniques. For more students to be accurately labeled as having an $\mathrm{LD}$, and for more students who do not have LD to have immediate and early access to responsive instruction, models that address early and intensive interventions must be used in schools and classrooms.

The field of LD is facing a desirable dilemma. The desirable part is that research-based techniques are available; the dilemma is that we do not yet know enough about how to ensure that those techniques become more widespread and universal practices. However, we do know some ways to overcome the obstacles and break through the barriers that prevent students with LD from receiving the best of what we do know works for them to progress.

How we take effective and responsive instruction for all learners to scale and how far we get with making that happen depends in part on how persistent and passionate we are about ensuring that all learners receive the best instruction we know of. It is encouraging and exciting to know that persistence and passion exist at all levels of education - from the parents to the classroom teachers, to the larger school system community, to higher education and researchers. Partnering with the educational, political, and policy communities is essential.

Clearly, the knowledge base about LD is richer today.
Tomorrow's visions encompass looking beyond school door boundaries and embracing lifelong success as the ultimate goal for individuals with LD. Our mission right now is to continue partnering and collaborating with stakeholders who share our vision: providing high-quality education for every student with $\mathrm{LD}$ in schools today to ensure that their capacity to achieve lifelong success is realized.

\section{REFERENCES}

* Bryan, T. (2003). The applicability of the risk and resilience model to the social problems of students with learning disabilities: Response to Bernice Wong. Learning Disabilities Research \& Practice, 18, 94-98.

* Coburn, C. E. (2003). Rethinking scale: Moving beyond numbers to deep and lasting change. Educational Researcher, 32(6), 3-12.

* Cosden, M. (2003). Response to Wong's paper. Learning Disabilities Research \& Practice, 18, 87-89.

* Denton, C. A., Foorman, B. R., \& Mathes, P. G. (2003). Perspective: Schools that "beat the odds." Remedial and Special Education, 24, 258-261.

* Denton, C. A., Vaughn, S., \& Fletcher, J. M. (2003). Bringing research-based practice in reading intervention to scale. Learning Disabilities Research \& Practice, 18, 201-211.

* Deshler, D. D. (2003). Intervention research and bridging the gap between research and practice. Learning Disabilities: A Contemporary Journal, 1(1), 1-7.

* Donahue, M. L., \& Pearl, R. (2003). Studying social development and learning disabilities is not for the faint-hearted: Comments on the risk/resilience framework. Learning Disabilities Research \& Practice, 18, 90-93.

Fuchs, D., Mock, D., Morgan, P. L., \& Young, C. L. (2003). Responsiveness-to-intervention: Definitions, evidence, and implications for the learning disabilities construct. Learning Disabilities Research \& Practice, 18, 157-171.

Gerber, P., Ginsberg, R., \& Reiff, H. B. (1992). Identifying alterable patterns of vocational success in highly successful adults with learning disabilities. Journal of Learning Disabilities, 25, 475-487.

Gersten, R., \& Jimenez, R. (1998). Promoting learning for culturally and linguistically diverse students. Belmont, CA: Wadsworth.

Goldenberg, C. N., \& Gallimore, R. (1991). Local knowledge, research knowledge, and educational change: A case study of early first-grade Spanish reading improvement. Educational Researcher, 20(8), 2-14.

* Klingner, J. K., Ahwee, S., Pilonieta, P., \& Menendez, R. (2003). Barriers and facilitators in scaling up research-based practices. Exceptional Children, 69, 411-429.

* Little, M. E., \& Houston, D. (2003). Research into practice through professional development. Remedial and Special Education, 24, 75-87.

MacMillan, D. L., \& Speece, D. L. (1999). Utility of current diagnostic categories for research and practice. In R. Gallimore, L. P. Bernheimer, D. L. MacMillan, D. L. Speece, \& S. Vaughn (Ed.), Developmental perspectives on children with highincidence disabilities (pp. 117-134). Mahwah, NJ: Lawrence Erlbaum Associates.

* Margalit, M. (2003). Resilience models among individuals with learning disabilities (LD): Proximal and distal influences. Learning Disabilities Research \& Practice, 18, 82-86.

* McNamara, J., \& Wong, B.Y.L. (2003). Memory for everyday information in students with learning disabilities. Journal of Learning Disabilities, 36, 394-406. 
Moody, W. W., Vaughn, S., Hughes, M. T., \& Fischer, M. (2000). Reading instruction in the resource room: Set up for failure. Exceptional Children, 66, 305-316.

No Child Left Behind Act of 2001, Pub. L. No. 107-110.

Raskind, M. H., Goldberg, R. J., Higgins, E. L., \& Herman, K. L. (1999). Patterns of change and predictors of success in individuals with learning disabilities: Results from a twenty-year longitudinal study. Learning Disabilities Research \& Practice, 14, 35-49.

* Robinson, C. S., Menchetti, B. M., \& Torgesen, J. K. (2002). Toward a two-factor theory of one type of mathematics disabilities. Learning Disabilities Research \& Practice, 17, 81-89.

Shaywitz, S. E., Shaywitz, B. A., Fletcher, J. M., \& Escobar, M. D. (1990). Prevalence of reading disability in boys and girls: Results of the Connecticut Longitudinal Study. Journal of the American Medical Association, 24, 998-1002.

Speece, D. L., \& Case, L. P. (2001). Classification in context: An alternative approach to identifying early reading disability. Journal of Educational Psychology, 93, 735-749.

Speece, D. L., Case, L. P., \& Molloy, D. E. (2003). Responsiveness to general education instruction as the first gate to learning disabilities identification. Learning Disabilities Research \& Practice, 18, 147-156.

* Sun, L., Bender, W. N., \& Fore, C. (2003). Web-based certification courses: The future of teacher preparation in special education? Teacher Education and Special Education, 26, 87-97.

* Tiu, R. D., Thompson, L. A., \& Lewis, B. A. (2003). The role of IQ in a component model of reading. Journal of Learning Disabilities, 36, 424-437.

United States Department of Education. (2003). Improving teacher quality: Non-regulatory guidance [revised draft issued September 12, 2003]. Washington, DC: Author.

United States Department of Education. (2004). Charting the course: States decide major provisions under No Child Left Behind. Retrieved January 20, 2004, from www.ed.gov/news/pressreleases/2004/01/01142004.html
* Vaughn, S., \& Fuchs, L. S. (2003). Redefining learning disabilities as inadequate response to instruction: The promise and potential problems. Learning Disabilities Research \& Practice, $18,137-146$

* Vaughn, S., Linan-Thompson, S., \& Hickman, P. (2003) Response to instruction as a means of identifying students with reading/learning disabilities. Exceptional Children, 69, 391-409.

* Vaughn, S., Linan-Thompson, S., Kouzekanani, K., Bryant, D. P., Dickson, S., \& Blozis, S. A. (2003). Reading instruction grouping for students with reading difficulties. Remedial and Special Education, 24, 301-315.

Vaughn, S., Moody, S. W., \& Schumm, J. S. (1998). Broken promises: Reading instruction in the resource room. Exceptional Children, 64, 211-225.

Werner, E. E. (1993). Risk and resilience in individuals with learning disabilities: Lessons learned from the Kauai longitudinal study. Learning Disabilities Research \& Practice, 8, 28-35.

* Wiener, J. (2003). Resilience and multiple risks: A response to Bernice Wong. Learning Disabilities Research \& Practice, 18, 77-81.

* Wong, B.Y.L. (2003). General and specific issues for researchers' consideration in applying the risk and resilience framework to the social domain of learning disabilities. Learning Disabilities Research and Practice, 18, 68-76.

Ysseldyke, J. E., Algozzine, B., \& Epps, S. (1983). A logical and empirical analysis of current practice in classifying students as handicapped. Exceptional Children, 50, 160-166.

* indicates a recommendation from a research panelist

Requests for reprints should be addressed to: Margaret E. KingSears, Johns Hopkins University, 9601 Medical Center Drive, Rockville, MD 20850; kingsear@jhu.edu. 